\title{
Development of Fluorinated Polymeric Functional Materials Using Fluorinated Organic Peroxide as Key Material
}

\author{
Hideo SAWADA ${ }^{\dagger}$ \\ Department of Frontier Materials Chemistry, Faculty of Science and Technology, \\ Hirosaki University, Bunkyo-cho, Hirosaki 036-8561, Japan
}

(Received February 20, 2007; Accepted March 26, 2007; Published May 29, 2007)

\begin{abstract}
Fluoroalkanoyl peroxide $\left[\mathrm{R}_{\mathrm{F}}-\mathrm{C}(=\mathrm{O}) \mathrm{OO}(\mathrm{O}=) \mathrm{C}-\mathrm{R}_{\mathrm{F}}\right]$ decomposes homolytically through concerted three bond radical fission to afford fluoroalkyl radical $\left(\mathrm{R}_{\mathrm{F}} \cdot\right)$ selectively, although the corresponding alkanoyl peroxide $[\mathrm{R}-\mathrm{C}(=\mathrm{O}) \mathrm{OO}(\mathrm{O}=) \mathrm{C}-\mathrm{R}]$ decomposes homolytically through stepwise radical fission to afford acyloxy radical [R$\mathrm{C}(=\mathrm{O}) \mathrm{O} \cdot$ ] and alkyl radical $[\mathrm{R} \cdot]$. This decomposition of fluoroalkanoyl peroxide was applied to the direct fluoroalkylation of two end-sites of vinylsilane oligomers and (meth)acrylate oligomers. Fluoroalkyl end-capped trimethoxyvinylsilane oligomers $\left[\mathrm{R}_{\mathrm{F}}-\left(\mathrm{CH}_{2} \mathrm{CHSi}(\mathrm{OMe})_{3}\right)_{\mathrm{n}}-\mathrm{R}_{\mathrm{F}}\right]$ thus obtained were applied to the surface modification on glass and traditional organic polymers such as PMMA and rubbers to exhibit not only strong hydrohobicity but good oleophobicity imparted by fluorine with extremely higher adhesive property on their surface. Fluoroalkyl end-capped actylate and methacrylate oligomers exhibited surface active properties imparted by fluorine, the same as for low-molecular weight fluorinated surfactants, and these fluorinated cooligomers formed the nanometer size-controlled self-assembled molecular aggregates in aqueous and organic media. These fluorinated molecular aggregates interacted with a variety of guest molecules such as low molecular biocides, fullerenes, and carbon nanotubes to afford the corresponding fluorinated oligomers/guest molecules nanocomposites. These fluorinated oligomers were applied to the preparation of fluorinated oligomers/silica gel nanocomposites and cross-linked fluorinated oligomeric nanoparticles.

[doi:10.1295/polymj.PJ2006242]

KEY WORDS Fluoroalkanoyl Peroxide / End-capped Fluoroalkyl Group / Carbon-carbon Bond Formation / Oligomer / Aggregation of Fluorine / Self-assembly / Oleophobicity / Surface Modification / Nanoparticle /
\end{abstract}

Randomly fluoroalkylated macromolecules such as acrylated, methacrylated and acrylamide polymers containing longer perfluoroalkyl groups exhibit interesting characteristics imparted by fluorine that set them apart from the usual alkylated macromolecules. ${ }^{1}$ Such randomly perfluoroalkylated polymers have in general relatively lower solubility in most solvents and are poor surfactants. ${ }^{2}$ Therefore, the exploration of surface active fluoroalkylated polymers leading to relatively high solubility in both water and common organic solvents including non-polar solvents should open a new route to the development of new functional materials, particularly new amphiphilic fluorinated polymeric materials. A considerable interest has been devoted in recent years to block copolymers containing fluoroalkyl groups owing to exhibiting the low surface energy and the self-assembled polymeric aggregates resembling micelle in aqueous and organic media, which cannot be achieved in the corresponding randomly fluoroalkylated copolymers. ${ }^{3}$ These longer perfluoroalkylated block copolymers have high potential for application to new fluorinated polysoaps. New fluorinated block copolymers have been recently pre- pared through RAFT (Reversible-Addition-Fragmentation-Transfer) and Atom Transfer Radical Polymerization (ATRP) techniques. ${ }^{4}$

However, in the longer fluoroalkylated polysoaps, these fluoroalkyl groups are in general introduced into polymeric molecules through ester groups owing to the synthetic difficulty of direct fluoroalkylation with carbon-carbon bond formation into polymeric molecules. Therefore, these fluorinated block copolymers have some difficulty to exhibit surface active characteristics imparted by fluoroalkyl groups on their surface for a long time, because these polymers are likely to undergo hydrolysis of the ester groups due to the strong electron negativity of fluorine. From the viewpoint of preparation and application of fluorinated block copolymers which should exhibit surface active properties imparted by longer perfluoroalkyl groups for a long time, it is very important to develop new preparative methods of fluorinated block copolymers with an excellent surfactant property, the same as for low-molecular weight fluorinated surfactants, in which fluoroalkyl groups should be directly introduced into polymeric molecules through carbon-car-

${ }^{\dagger}$ To whom correspondence should be addressed (Tel: +81-172-39-3578, Fax: +81-172-39-3541, E-mail: hideosaw@cc.hirosaki-u.ac.jp). 
bon bond formation. This paper demonstrates the synthesis and application of new fluoalkylated polymers with carbon-carbon bond formation using fluoroalkanoyl peroxide as key intermediate.

\section{THERMAL DECOMPOSITION OF FLUOROALKANOYL PEROXIDES AND SYNTHETIC APPROACH TO NEW FLUOROALKYL END-CAPPED OLIGOMERS USING THESE PEROXIDES}

We previously reported comprehensive studies on the synthesis and thermal decomposition of fluorinated peroxides. ${ }^{5}$ Among these fluorinated peroxides, interesting decomposition of fluoroalkanoyl peroxides was noted: large rate enhancements were observed in the thermal decomposition of fluoroalkanoyl peroxides in contrast to the corresponding non-fluorinated peroxides, as shown in Table I. $^{6}$ In the thermal decomposition of fluoroalkanoyl peroxides, peroxide (Run 1 in Table I) was found to afford the higher homolytic decomposition rates (10 hours half life temperature: $\left.-8.7^{\circ} \mathrm{C}\right)$. We believe that this half life temperature is the lowest value in organic peroxides which could exhibit radical decomposition. The activation enthalpy for the decomposition of fluoroalkanoyl peroxide $\left(\Delta \mathrm{H}^{\neq}=21-26 \mathrm{kcal} / \mathrm{mol}\right)$ is lower than that of the corresponding nonfluorinated alkanoyl peroxide $\left(\Delta \mathrm{H}^{\neq}=\sim 29 \mathrm{kcal} / \mathrm{mol}\right)$ by $3-8 \mathrm{kcal} / \mathrm{mol}{ }^{5 \mathrm{a}}$ The acceleration of the decomposition rate or decrease in activation enthalpy may possibly arise from the stability of fluoroalkyl radicals in fluoroalkanoyl peroxides leading to a concerted dissociation with a three-bond radical fission, although the corresponding nonfluorinated peroxide affords a stepwise radical fission as shown in Scheme 1.5 The decomposition of fluoroalkanoyl peroxides selectively affords the corresponding coupling products $\left(\mathrm{R}_{\mathrm{F}}-\mathrm{R}_{\mathrm{F}}\right)$ in good yields (see Scheme 1). ${ }^{5}$
As shown in Table II, the introduction of fluoroalkyl group into alkanoyl peroxide weakens the $\mathrm{O}-\mathrm{O}$ peroxy bond $\left(-{ }^{5} \mathrm{O}-{ }^{1} \mathrm{O}-\right)$ as well as the $\mathrm{C}^{2}-\mathrm{C}^{4}$ bond. The introduction of fluoroalkyl group into alkanoyl peroxide makes both $\mathrm{O}-\mathrm{O}$ and $\mathrm{C}^{2}-\mathrm{C}^{4}$ bonds weaker than those of the corresponding nonfluorinated peroxide. $^{7}$ This should accelerate decarboxylation and $\mathrm{O}-\mathrm{O}$ cleavage in a homolytic fashion to afford the corresponding fluoroalkyl radical as illustrated in Scheme 1.

Another specific fluoroalkanoyl peroxide characteristric is that fluoroalkanoyl peroxides lower the $2 \mathrm{p} \sigma^{*}(\mathrm{O}-\mathrm{O})$ antibonding orbital considerably compared to that of nonfluorinated peroxides (see Table II and Figure 1). ${ }^{7}$ Therefore, fluoroalkanoyl peroxide

Table I. Thermal Decomposition of $(\mathrm{RCOO})_{2}$

\begin{tabular}{|c|c|c|c|}
\hline Run & & $\begin{array}{c}k_{\mathrm{d}}\left[\mathrm{s}^{-1}\right] \times 10^{8} \\
\left(25^{\circ} \mathrm{C}\right)\end{array}$ & $10 \mathrm{~h} t_{1 / 2}\left({ }^{\circ} \mathrm{C}\right)$ \\
\hline 1 & & $187200^{a)}$ & -8.7 \\
\hline 2 & & $18600^{\mathrm{b})}$ & 8.2 \\
\hline 3 & $\mathrm{C}_{6} \mathrm{~F}_{13} \mathrm{OCF}\left(\mathrm{CF}_{3}\right)$ & $12100^{\mathrm{a})}$ & 12.4 \\
\hline 4 & $\mathrm{C}_{10} \mathrm{~F}_{21} \mathrm{OCF}\left(\mathrm{CF}_{3}\right)$ & $11100^{*), a)}$ & 13.4 \\
\hline 5 & $\mathrm{~F}_{3} \mathrm{C}$ & $7920^{*), a)}$ & 13.7 \\
\hline 6 & $\mathrm{C}_{3} \mathrm{~F}_{7} \mathrm{OCF}\left(\mathrm{CF}_{3}\right)-$ & $8990^{c)}$ & 15.1 \\
\hline 7 & $\mathrm{CF}_{3}(\mathrm{CF})_{6-}$ & $5860^{c)}$ & 17.6 \\
\hline 8 & $\mathrm{CF}_{3} \mathrm{CF}_{2} \mathrm{CF}_{2}-$ & $3320^{\mathrm{c})}$ & 28.1 \\
\hline 9 & & $204^{\mathrm{d})}$ & 41.3 \\
\hline 10 & $\mathrm{CF}_{3}-$ & $100^{\mathrm{c})}$ & 46.3 \\
\hline 11 & $\mathrm{CH}_{3} \mathrm{CH}_{2} \mathrm{CH}_{2}-$ & $4^{c)}$ & \\
\hline
\end{tabular}

*) Temp: $26^{\circ}$ C. a) See Ref. 6-a $\sim$ c). b) See Ref. 6-d). c) See Ref. 5). d) See Ref. 6-e).

[l] Fluoroalkanoyl Peroxide

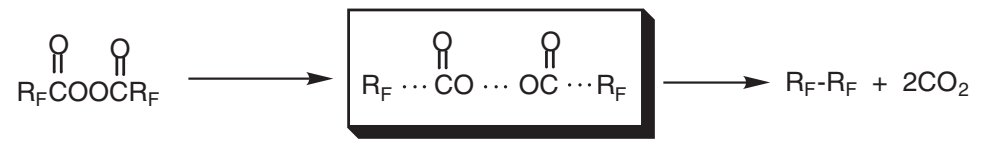

[II] Alkanoyl Peroxide

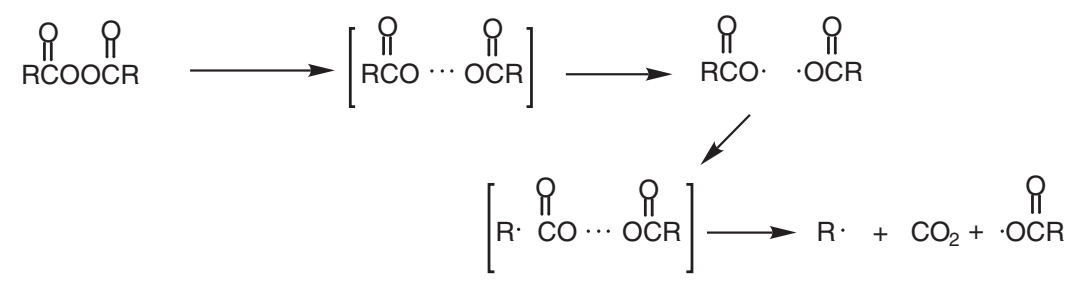

Scheme 1. 
Table II. Rate of Decomposition (in $\mathrm{sec}^{-1}$ ) and Some Electronic Properties (in eV) of Alkanoyl Peroxides; Numbering of Atoms for Alkanoyl Peroxides:

\begin{tabular}{|c|c|c|c|c|}
\hline R- & $\begin{array}{c}k_{\mathrm{d}}\left[\mathrm{s}^{-1}\right] \times 10^{8} \\
\left(25^{\circ} \mathrm{C}\right)\end{array}$ & $E^{R}{ }_{1-5}$ & $\mathrm{E}^{\mathrm{R}}{ }_{2-4}$ & $\varepsilon_{\text {LUMO }}$ \\
\hline & 187200 & -8.932 & -12.461 & -2.460 \\
\hline & 18600 & -8.800 & -12.044 & -2.660 \\
\hline $\mathrm{C}_{6} \mathrm{~F}_{13} \mathrm{OCF}\left(\mathrm{CF}_{3}\right)$ & 12100 & -8.596 & -12.048 & -2.538 \\
\hline $\mathrm{CF}_{3}(\mathrm{CF})_{6-}$ & 5860 & -8.712 & -11.879 & -2.560 \\
\hline $\mathrm{CF}_{3} \mathrm{CF}_{2} \mathrm{CF}_{2}-$ & 3320 & -8.717 & -11.906 & -2.513 \\
\hline $\mathrm{CF}_{3}-$ & 100 & -8.719 & -11.900 & -2.384 \\
\hline $\mathrm{CH}_{3} \mathrm{CH}_{2} \mathrm{CH}_{2}-$ & 4 & -8.978 & -13.014 & -0.598 \\
\hline $\mathrm{CH}_{3}-$ & 2 & -8.964 & -13.205 & -0.635 \\
\hline
\end{tabular}

a) $26^{\circ} \mathrm{C}$

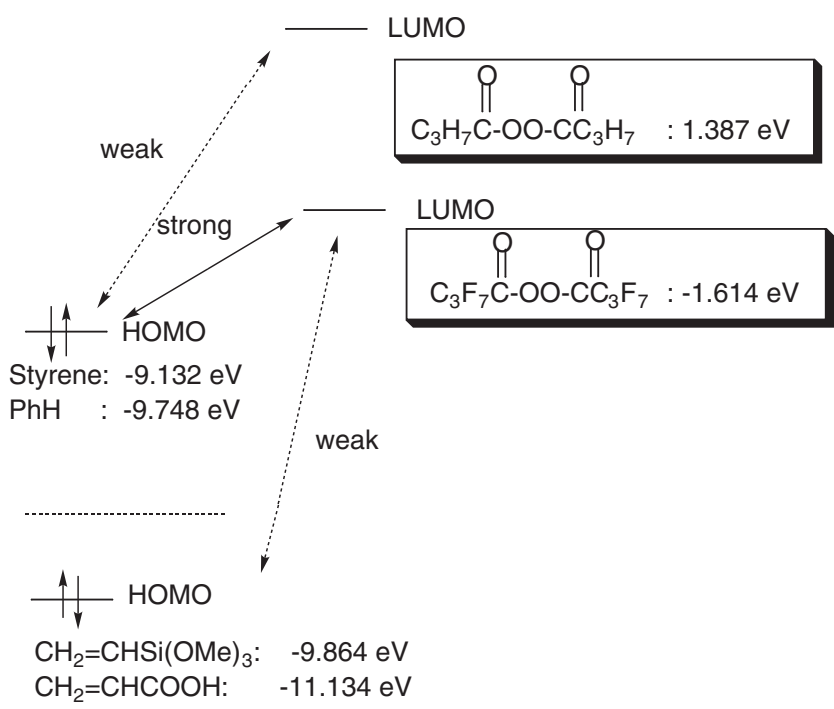

Figure 1. LUMO enrgy levels of perfluorobutyryl peroxide and butyryl peroxide, together with the HOMO-LUMO interactions.

should prose a useful electron acceptor even from well-known relatively poor electron-donor aromatic compounds such as benzene and chlorobenzene. The presence of two strong electron-withdrawing groups in alkanoyl peroxides greatly weakens the $\mathrm{O}-\mathrm{O}$ bond in addition to lowering the energy level of the antibonding $\mathrm{O}-\mathrm{O}$ bond compared to the corresponding nonfluorinated peroxides. This unique property of fluoroalkanoyl peroxide was thus applied to the introduction of fluoroalkyl groups into various aromatic compounds such as benzenes, and heteroaromaic compounds such as thiophenes, furans, benzofuran

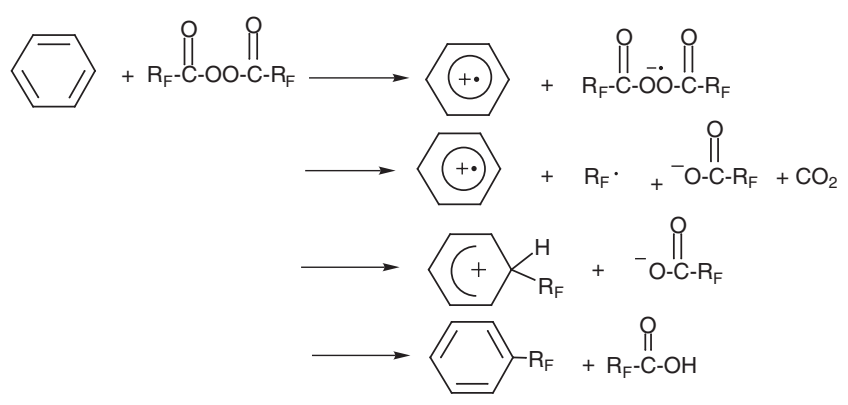

Scheme 2.

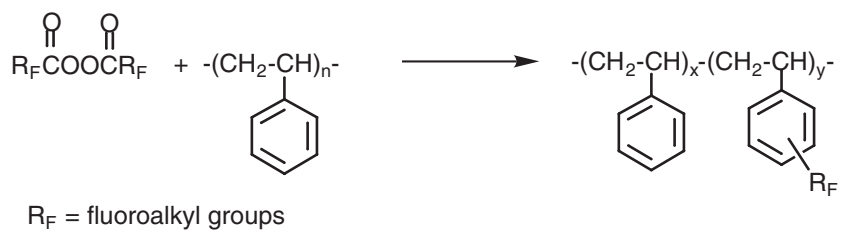

Scheme 3.

and benzothiophene via a single electron-transfer process under mild conditions. ${ }^{8}$

Fluoroalkanoyl peroxides were found useful reagents for the direct aromatic fluoroalkylation of polymers such as polystyrene, polydiphenylsilane, polydiphenylsiloxane, polyimide, and polyamic acid through the HOMO (aromatic polymers) and LUMO (peroxide) interaction (single electron transfer reaction). ${ }^{8}$

Styrene is a useful radical polymerizable monomer, and diacyl peroxides such as benzoyl peroxide and alkanoyl peroxide are widely used as conventional radical initiators, because since the interaction between the LUMO of diacyl peroxide (e.g. butyryl peroxide) and the HOMO of styrene become extremely weak compared to that of perfluorobutyryl peroxide (see Figure 1), the interaction of the SOMO of acyloxy radicals, which produce in the radical decomposition of diacyl peroxides, should interact with the HOMO of styrene to afford the radical polymerization of styrene. In contrast, styrene reacted with fluoroalknoyl peroxides to afford not the radical polymerizable products but $1: 1$ adducts $\left[\mathrm{PhCH}\left(\mathrm{OCOR}_{\mathrm{F}}\right) \mathrm{CH}_{2} \mathrm{R}_{\mathrm{F}}\right]$ via a single electron transfer from the HOMO of styrene to the LUMO of peroxide. ${ }^{8}$

Large rate enhancement was observed in the thermal decompositions of fluoroalkanoyl peroxides in contrast to the corresponding non-fluorinated peroxides, indicating fluoroalkanoyl peroxides decompose with three-bond radical fission to afford fluoroalkyl radicals $\left(\mathrm{R}_{\mathrm{F}} \cdot\right)$. As shown in Figure 1, it is strongly expected that monomers such as acrylic acid and trimethoxyvinylsilane, which could possess lower HOMO energy levels compared to styrene, should interact with the SOMO of $\mathrm{R}_{\mathrm{F}} \cdot$ radical derived from the thermal decomposition of fluoroalkanoyl peroxides. This 


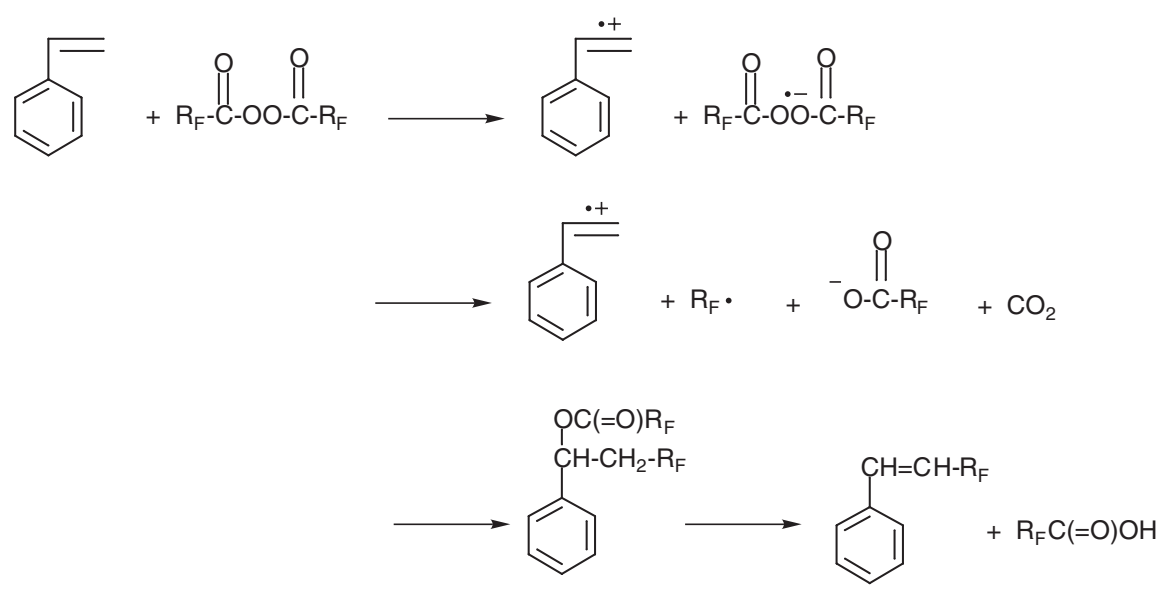

Scheme 4.

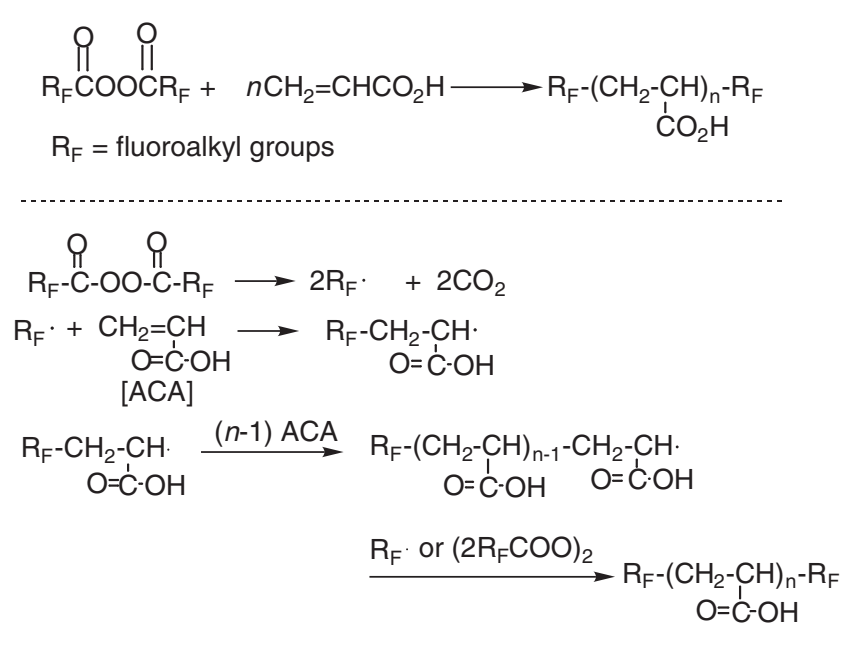

Scheme 5.

suggests that fluoroalkanoyl peroxide is a convenient means for the direct introduction of the corresponding fluoroalky groups into organic molecules via a radical process. In fact, as shown in Scheme 5, we succeeded in preparing two fluoroalkyl end-capped acrylic acid oligomers by the reactions of acrylic acid with fluoroalkanoyl peroxides as key intermediates. ${ }^{9}$

Under our oligomeric conditions, in which the concentration of the peroxide was almost the same as that of acrylic acid, mainly acrylic acid oligomers with two fluoroalkyl end groups were obtained via primary radical termination or radical chain transfer to the peroxide (see Scheme 5). Elementary analysis for fluorine confirmed that these oligomers contain two fluoroalkylated end-groups in one molecule. ${ }^{10}$

Vinylsilanes are poorly radical polymerizable; ${ }^{11}$ however, fluoroalkanoyl peroxides react with vinylsilanes to afford two fluoroalkyl end-capped vinylsilane oligomers (mixtures of dimer and trimers) by the homolytic decomposition of peroxide and by chain transfer to the peroxide as shown in the following Scheme $6 .^{12}$

In this way, fluoroalkanoyl peroxide is convenient

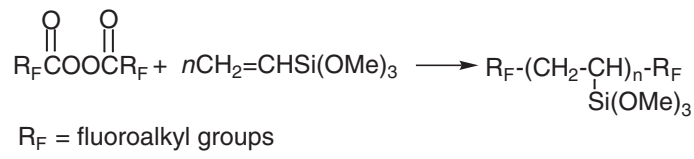

Scheme 6 .

for the preparation of a wide variety of fluoroalkyl end-capped oligomers with carbon-carbon bond formation by the oligomerization of the peroxide with radical polymerizable monomers via a radical process. Fluoroalkyl end-capped acrylic acid oligomers were found attractive functional materials due to various unique properties such as a high solubility, surface active properties and the formation of self-assembled molecular aggregates, not possible by the corresponding randomly fluoroalkylated polymers and fluoroalkylated block polymers, in which fluoroalkyl groups are introduced through ester groups. ${ }^{13}$

\section{APPLICATION TO THE SURFACE MODIFICATION OF FLUOROALKYL END- CAPPED TRIMETHOXYVINYLSILANE OLIGOMERS}

Organosilicon compounds exhibit good hydrophobic but not oleophobic properties. In contrast, organofluorine compounds bearing long fluoroalkyl chains have not only hydrophobic but also oleophobic properties. Hence, there is great need for the development of new functional materials possessing excellent properties imparted by both silicon and fluorine. ${ }^{14}$ The hydrosilylation of fluorine-containing alkenes promoted by organotransition metal catalysts such as platinum complex is applicable for the synthesis of fluoroalkylated silane coupling agents such as $\mathrm{R}_{\mathrm{F}}-\mathrm{CH}_{2} \mathrm{CH}_{2}$ $\left.\mathrm{Si}(\mathrm{OMe})_{3}\right] .{ }^{15}$ These fluorinated silane coupling agents are useful as surface-active materials, and have been applied to various practical fields. Our present two fluoroalkyl end-capped oligomeric silane coupling 


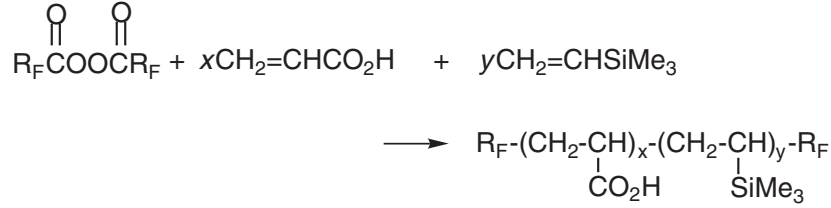

$\mathrm{R}_{\mathrm{F}}=\mathrm{C}_{3} \mathrm{~F}_{7}, \mathrm{CF}\left(\mathrm{CF}_{3}\right)\left[\left(\mathrm{OCF}_{2} \mathrm{CF}\left(\mathrm{CF}_{3}\right)\right]_{\mathrm{m}} \mathrm{OC}_{3} \mathrm{~F}_{7} ; \mathrm{m}=0,1,2\right.$

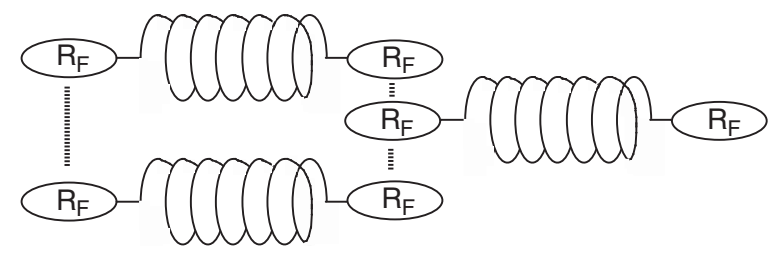

Figure 2. Schematic model of micelles formed with fluoroalkyl end-capped acrylic acid-trimethylvinylsilane cooligomers.

Scheme 7.

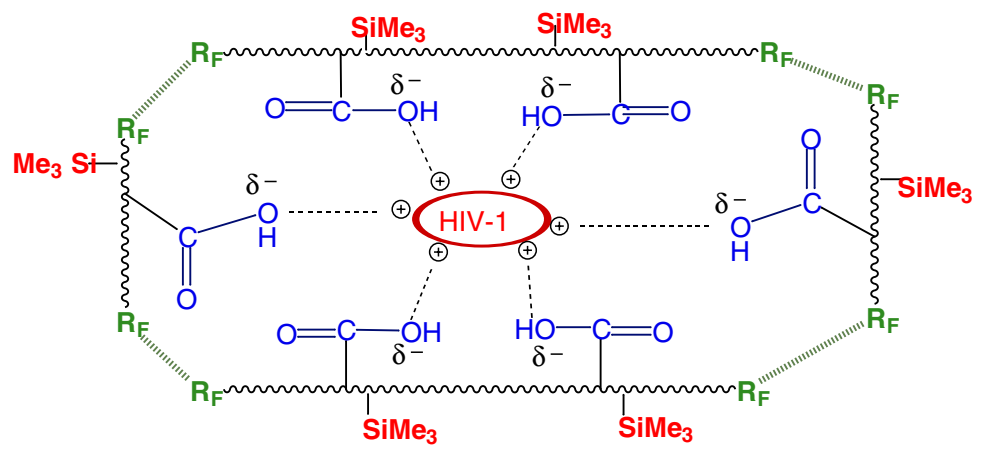

Figure 3. Schematic illustration for interaction of HIV-1 with aggregates formed by $\mathrm{R}_{\mathrm{F}}-\left(\mathrm{CH}_{2}-\mathrm{CHCO}_{2} \mathrm{H}\right)_{\mathrm{x}}-\left(\mathrm{CH}_{2}-\mathrm{CHSiMe}_{3}\right)_{\mathrm{y}}-\mathrm{R}_{\mathrm{F}}$.

agents $\left[\mathrm{R}_{\mathrm{F}}-\left[\mathrm{CH}_{2} \mathrm{CHSi}(\mathrm{OMe})_{3}\right]_{\mathrm{n}}-\mathrm{R}_{\mathrm{F}}\right]$ in Scheme 6 exhibited a more surface active characteristic compared to the above traditional fluorinated silane coupling agents. ${ }^{12}$ Our fluorinated oligomeric silane coupling agents exhibited extremely higher adhesiveness on glass and rubber surfaces than traditional fluorinated silane coupling agents. ${ }^{16}$

\section{AGGREGATION OF FLUOROALKYL END-CAPPED OLIGOMERS-FORMATION OF NANOMETER SIZE-CONTROLLED FLUORINATED OLIGOMERIC AGGREATES}

Fluoroalkyl end-capped acrylic acid-trimethylvinylsilane cooligomers, prepared by the cooligomerization of fluoroalkanoyl peroxides with the corresponding monomers, were amphiphilic (see Scheme 7).${ }^{17}$ These fluoroalkyl end-capped cooligomers form molecular aggregates resembling normal and reverse micelles in water and organic solvents, respectively. ${ }^{18}$ Static light scattering measurements showed that molecular assemblies formed in aqueous solution of fluoroalkyl end-capped acrylic acid-trimethylvinylsilane cooligomers are ellipsoidal with the aggregation of terminal fluoroalkyl groups as shown in the following (see Figure 2). ${ }^{18}$

These molecular aggregates provide suitable host moieties to interact with positively charged HIV-1 through electrostatic interaction, and fluoroalkyl endcapped acrylic acid-trimethylvinylsilane cooligomers were found to exhibit potent and selective anti-HIV1 activity (see Figure 3). ${ }^{19}$

We prepared various fluoroalkyl end-capped 2acrylamide-2-methylpropanesulfonic acid [AMPS]

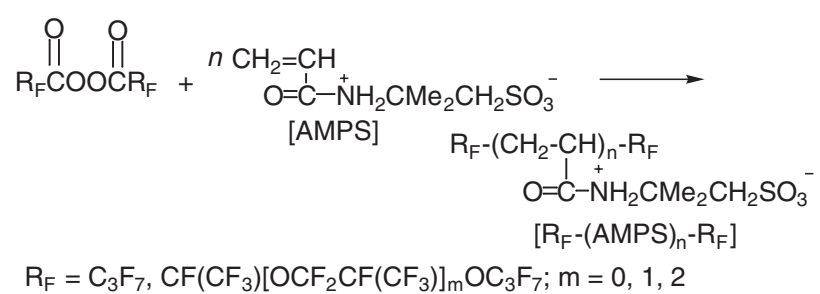

Scheme 8.

oligomers using fluoroalkanoyl peroxides as shown in Scheme 8. ${ }^{20}$

The fluoroalkyl end-capped AMPS oligomers formed gels not only in water but also in organic polar solvents such as methanol, ethanol, N,N-dimethylformamide (DMF), and dimethyl sulfoxide (DMSO) under non-crosslinked conditions. Fluoroalkylene units-containing AMPS oligomer $\left\{\left[-\mathrm{R}_{\mathrm{F}}-(\mathrm{AMPS})_{\mathrm{q}}\right]_{\mathrm{p}^{-}}\right\}$ caused no gelation under similar conditions. ${ }^{20}$ Fluoroalkyl end-capped AMPS polymers thus possibly may cause gelation where strong aggregation of the end-capped fluoroalkyl groups is involved in establishing the physical gel network in these media. Longer fluoroalkylated compounds exhibit strong repellency toward water or hydrocarbons owing to the strong electronegativity of fluorine. However, as shown in Figure 4, the fluoroalkyl groups in fluoroalkyl end-capped AMPS oligomers aggregate easily with each other rather than have repellent interactions in aqueous or organic media since fluoroalkyl groups are introduced only at oligomer end-sites. These fluoroalkyl end-capped oligomers cause gelation by synergistical interaction of the aggregation of fluoroalkyl 


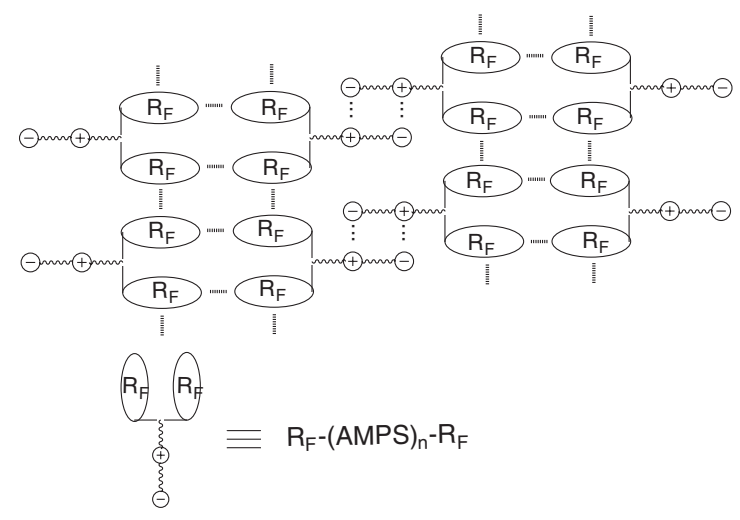

Figure 4. Schematic illustration for gelation of $R_{F}-(A M P S)_{n}-$ $\mathrm{R}_{\mathrm{F}}$.

groups and the ionic interaction of the betaine segments. These gelling fluorinated AMPS oligomers are potent and selective inhibitors of HIV-1 replication in vitro and in vivo. ${ }^{21}$

Gelling fluoroalkyl end-capped oligomers containing betaine segments should possess not only high conductivity but also various unique properties such as excellent chemical and thermal stability, low surface energy, low refractive index and dielectric constant imparted by fluorine. New fluoroalkyl end-capped AMPS cooligomers containing poly(oxyethylene) units were prepared with fluoroalkanoyl peroxides. ${ }^{22}$ The fluorinated cooligomers form gels in DMSO under non-crosslinked conditions, and fluorinated oligomer gelling electrolytes containing lithium salts exhibit considerably high ionic conductivity of $10^{-3}$ $\mathrm{S} / \mathrm{cm}$ at room temperature. ${ }^{22}$

\section{PREPARATION AND APPLICATION OF FLUOROALKYL END-CAPPED OLIGOMERIC NANOCOMPOSITES}

Our fluoroalkyl end-capped oligomers form nanometer size-controlled self-assembled molecular aggregates in aqueous and organic media. Fluorinated oligomers provide suitable host moieties with the aggregation of terminal fluoroalkyl segments in oligomers to interact with various guest molecules as shown in Figure 5. ${ }^{23}$ The corresponding non-fluorinated oligomers do not form such molecular aggregates, and the fluorinated oligomers have weak entanglement interaction (see Figure 5). Thus, interactions of selfassembled molecular aggregates formed by fluoroalkyl end-capped oligomers containing recognition moieties with various guest molecules should be studied.

We investigated the potential of fluorinated $\mathrm{N}$ (1,1-dimethyl-3-oxobutyl)acrylamide oligomers $\left[\mathrm{R}_{\mathrm{F}}-\right.$
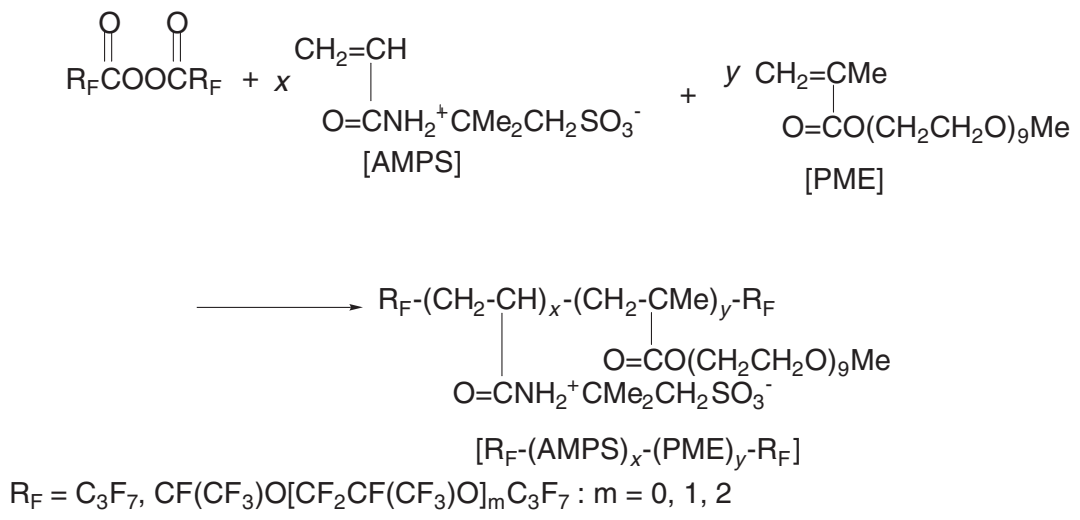

Scheme 9.

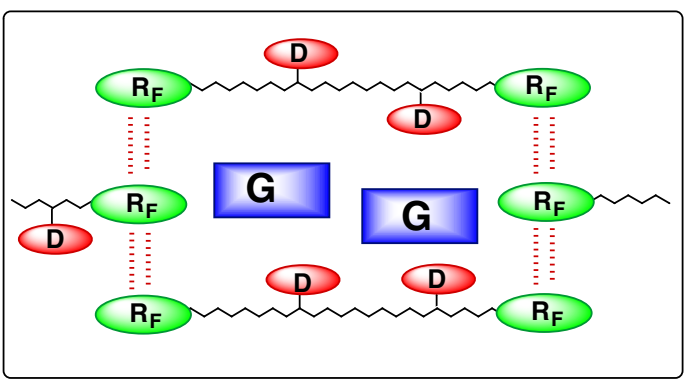

[A] Fluorinated Oligomer

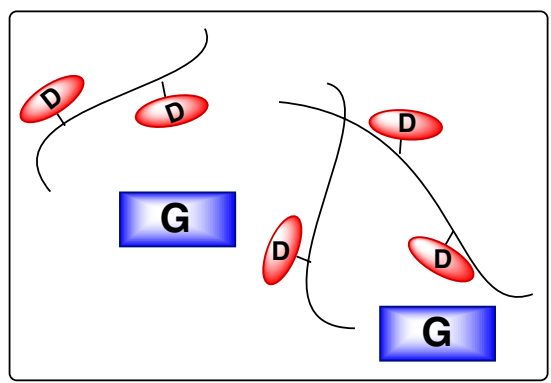

[B] Non-fluorinated Oligomer

G : Guest Molecule

Figure 5. Schematic illustration for interaction of self-assembled fluoroalkyl end-capped oligomers with guest molecules. 


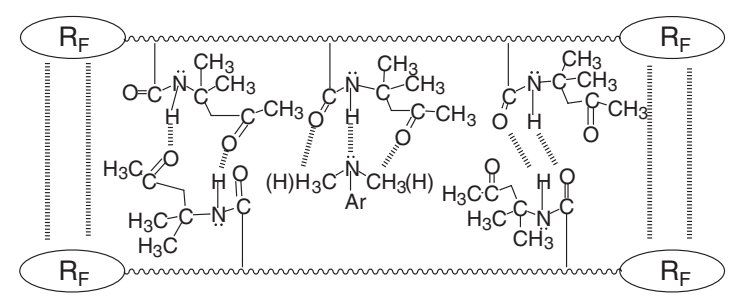

Figure 6. Schematic illustration for the recognition of hydrophilic amino compounds $\left[\mathrm{ArN}\left(\mathrm{CH}_{3}\right)_{2}\right.$ (or $\left.\left.\mathrm{ArNH}_{2}\right)\right]$ by self-assembled aggregates of $\mathrm{R}_{\mathrm{F}}-(\mathrm{DOBAA})_{\mathrm{n}}-\mathrm{R}_{\mathrm{F}}$.

(DOBAA) $\left.{ }_{n}-R_{F}\right]$ as a host system for polar guests in organic media. $\mathrm{R}_{\mathrm{F}}-(\mathrm{DOBAA})_{\mathrm{n}}-\mathrm{R}_{\mathrm{F}}$ oligomer transferred methylene blue quantitatively (97\%) from aqueous solution into 1,2-dichloroethane by the liquid-liquid extraction. ${ }^{25}$ However, the corresponding nonfluorinated DOBAA oligomer [-(DOBAA) $\mathrm{n}^{-}$] did not transfer methylene blue into 1,2-dichloroethane at all under similar conditions. Fluoroalkyl end-capped DOBAA oligomers thus provides the most suitable host moiety for methylene blue. $\mathrm{R}_{\mathrm{F}}-(\mathrm{DOBAA})_{\mathrm{n}}-\mathrm{R}_{\mathrm{F}}$ oligomeric aggregates extracted not only methylene blue but also methyl orange, and acriflavine hydrochloride, effectively. This oligomer was not able to extract hydrophilic polar guests such as 4-hydroxyazobenzene-4'-sulfonic acid sodium salt, 2,4-dihydroxyazobenzene-4'-sulfonic acid sodium salt, acridine hydrochloride or lucigenin. Thus, possibly, fluorinated molecular assemblies formed by the DOBAA oligomer recognize hydrophilic amino and N,Ndimethylamino compounds. An acidic amido proton $[-\mathrm{C}(=\mathrm{O})-\mathrm{NH}-]$ and carbonyl segments in the aggregates of $\mathrm{R}_{\mathrm{F}}-(\mathrm{DOBAA})_{\mathrm{n}}-\mathrm{R}_{\mathrm{F}}$, constructed by the aggregations of end-capped fluoroalkyl segments and the inter-molecular hydrogen bondings of the amido and carbonyl segments, may interact with a basic amino or $\mathrm{N}, \mathrm{N}$-dimethylamino nitrogen [: $\mathrm{NH}_{2}-\mathrm{Ar}$ or $: \mathrm{NMe}_{2}-$ $\mathrm{Ar}]$ and a proton(or a methyl proton) of guest molecules, respectively, through inter-molecular hydrogen bonding as shown in Figure $6{ }^{24}$

Self-assembled molecular aggregates of fluoroalkyl end-capped $\mathrm{N}$-(1,1-dimethyl-3-oxobutyl)acrylamide oligomers provide nanometer size-controlled suitable host moieties to interact with low-molecular biocides as guest molecules. ${ }^{25}$ These fluorinated molecular aggregates-biocide nanocomposites are applicable for surface modification of traditionally organic polymers. ${ }^{25}$ The modified polymer film surface exhibited not only an surface activity imparted by end-capped fluoroalkyl groups in oligomers but also good surface antibacterial activity related to the presence of hibitane $\left[1,1^{\prime}\right.$-hexamethylenebis[(5-(4-chlorophenyl)biguanide) dihydrochloride], a derivative of guanidine. This compound is a potent low-molecular weight biocide in composites. ${ }^{25}$

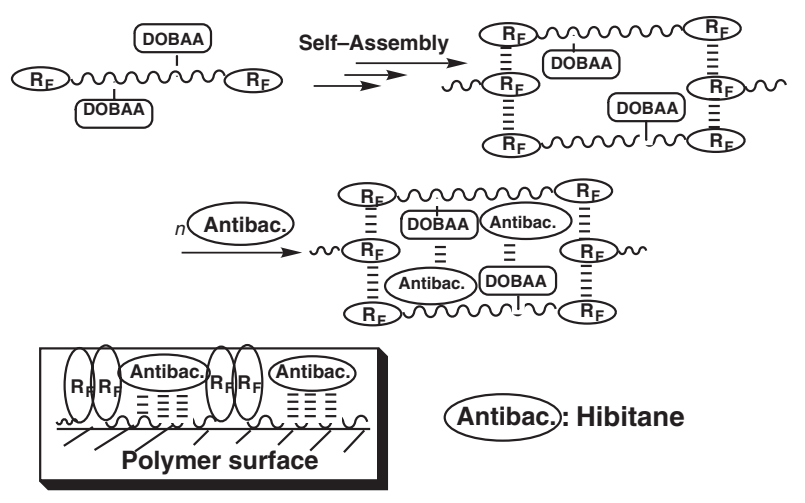

Figure 7. Interactions of hibitane with self-assembled molecular aggregates of fluoroalkyl end-capped $N$-(1,1-dimethyl-3-oxobutyl)acrylamide oligomers-good surface antibacterial activity on polymer surface with oleophobicity due to fluorine.

Studies on the preparation of organic nanoparticles are very limited due to preparative difficulties. The most popular preparative method of organic nanoparticles is reprecipitation. ${ }^{26}$ Biphenyl ethylene derivatives in mixture of water/terahydrofuran aggregate into nanosize controlled particles with a mean diameter of about $30-40 \mathrm{~nm}$ through the reprecipitation method. ${ }^{27} \mathrm{R}_{\mathrm{F}}$-(DOBAA) $\mathrm{n}_{\mathrm{n}}-\mathrm{R}_{\mathrm{F}}$ oligomers provide nanometer-size controlled fluorinated aggregate cores, which interact selectively with fluorescein as a guest molecule through intermolecular hydrogen bonding to afford new-type fluorinated oligomers/fluorescein nanocomposites. ${ }^{28}$

Applications of fullerenes into a wide variety of fields have been very limited owing to poor solubility in polar solvents including water. ${ }^{29}$ Thus, it is very important to solubilize fullerenes in water by surfactants. Yamakoshi et al. reported poly(vinylpyrrolidone) [PVP], a useful non-ionic polysoap, to be useful for the solubilization of fullerene in water. ${ }^{30}$ Fluorinated molecular assemblies formed by fluoroalkyl end-capped oligomers such as fluorinated acryloylmorpholine oligomers should interact with fullerene through van der Waals interaction to exhibit good solubility in water. We solubilized fullerene in water using fluoroalkyl end-capped acryloylmorpholine oligomers to afford fluorinated oligomers/fullerenes nanocomposites. ${ }^{31}$ These nanocomposites were applied to surface modification of traditional organic polymers such as PMMA. Fluoroalkyl end-capped oligomers in nanocomposites were arranged regularly above the modified PMMA surface owing to strong oleophobicity imparted by fluoroalkyl groups and the good affinity of fluoroalkyl groups toward the air (see Figure 8). Fullerene should thus also be arranged regularly above the modified PMMA surface through interaction of the self-assembled aggregates of fluorinated oligomers with fullerene (see Figure 8). ${ }^{32}$ 


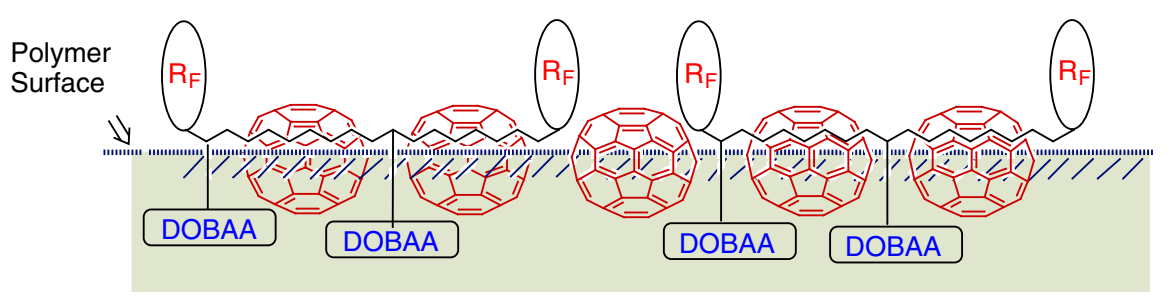

Figure 8. Schematic illustration for the arrangement of fluoroalkyl end-capped DOBAA oligomer-fullerenes above the polymer surface.

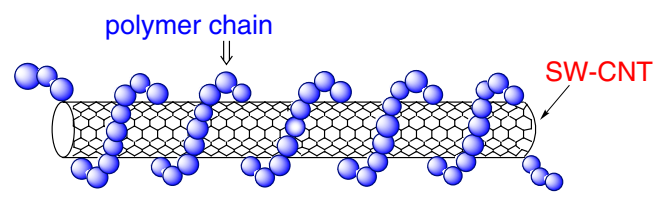

Figure 9. Schematic illustration for the interaction of watersoluble polymers with SW-CNT for the solubilization of SWCNT in water.

Applications of carbon nanotubes [CNTs] to various fields have been very limited due to insolubility in water and most common organic solvents. ${ }^{33}$ Thus, it is very important to solubilize CNTs in aqueous and organic media using polymeric surfactants. Smalley et al. reported that PVP can dissolve singlewalled carbon nanotube (SW-CNT) in water by polymer wrapping as shown in Figure 9. ${ }^{34}$

Functionalization of SW-CNTs by the introduction of longer fluoroalkyl groups is of particular interest from developmental viewpoints of highly soluble CNTs derivatives. Fluoroalkanoyl peroxides react with SW-CNT under very mild conditions to afford fluoroalkylated SW-CNT derivatives. ${ }^{35}$ Similarly, fluoroalkanoyl peroxides react with SW-CNT in the presence of radical polymerizable monomers such as acryloylmorpholine (ACMO), $N, N$-dimethylacrylamide (DMAA) and DOBAA to afford fluoroalkyl end-capped cooligomers having SW-CNT units in the main chains (see Scheme 10). ${ }^{35}$

Fluoroalkyl end-capped SW-CNT cooligomers thus obtained were found to exhibit good solubility not only in water but also in traditional organic solvents such as methanol, ethanol, THF, chloroform, benzene, toluene, ethyl acetate, 1:1 mixed solvents of 1,1-dichloro-2,2,3,3,3-pentafluoropropane and 1,3dichloro-1,2,2,3,3-pentafluoropropane (fluorinated aliphatic solvents), dimethyl sulfoxide, $N, N$-dimethylformamide, acetone and dichloromethane through not hexane. ${ }^{35}$ Fluoroalkyl end-capped SW-CNT cooligomers possessing good solubility may form selfassembled molecular aggregates in aqueous media as well as the corresponding fluoroalkyl end-capped homooligomers having no SW-CNT units.

$\mathrm{R}_{\mathrm{F}}-(\mathrm{ACMO})_{\mathrm{x}}-(\mathrm{SW}-\mathrm{CNT})_{\mathrm{y}}-\mathrm{R}_{\mathrm{F}}$ cooligomer is more effective for solubilizing SW-CNT into water about 3 times compared to that of the corresponding fluoroalkyl end-capped acryloylmorpholine homooligomer $\left[\mathrm{R}_{\mathrm{F}}-(\mathrm{ACMO})_{\mathrm{n}}-\mathrm{R}_{\mathrm{F}}\right]^{35}$

Fluoroalkanoyl peroxide was recently shown useful for preparing fluoroalkyl end-capped vinylsilane oligomer containing vinyldimethylsiloxane segments as shown in Scheme 11. ${ }^{36}$ This fluorinated oligomer was applied to the preparation of novel fluorinated block copolymers. The fluorinated block copolymers thus obtained formed the dendritic-type unimolecular micelles in aqueous solutions to provide new fluorinated host moieties. The fluorinated host moieties interacted with fullerenes as guest molecules to give an extremely higher solubility of fullerene in water than that of traditional fluoroalkyl end-capped oligomeric aggregates. ${ }^{36}$

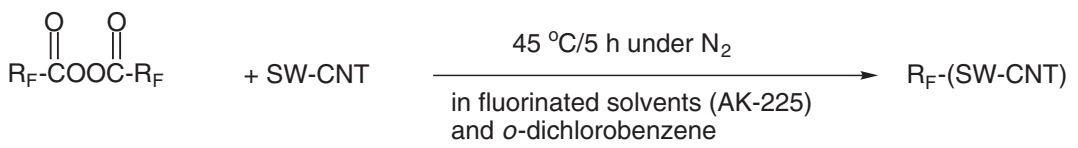

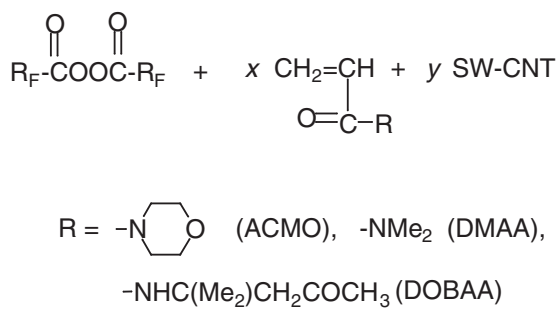

$45^{\circ} \mathrm{C} / 5$ h under $\mathrm{N}_{2}$

in fluorinated solvents (AK-225) and $o$-dichlorobenzene

$$
\begin{aligned}
& \mathrm{R}_{\mathrm{F}}-\left(\mathrm{CH}_{2}-\mathrm{CH}\right)_{x}-(\mathrm{SW}-\mathrm{CNT})_{y}-\mathrm{R}_{\mathrm{F}} \\
& \mathrm{O}=\mathrm{C}-\mathrm{R} \\
& \mathrm{R}_{\mathrm{F}}=\mathrm{CF}\left(\mathrm{CF}_{3}\right) \mathrm{OCF}_{2} \mathrm{CF}\left(\mathrm{CF}_{3}\right) \mathrm{OC}_{3} \mathrm{~F}_{7}
\end{aligned}
$$

Scheme 10. 


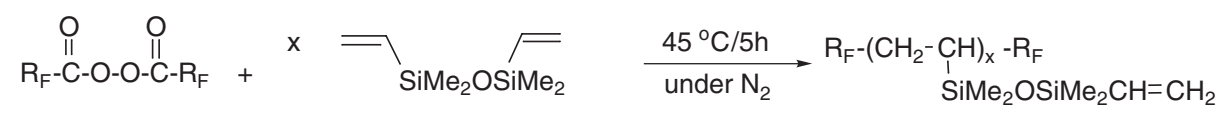

$$
\begin{aligned}
& \mathrm{R}_{\mathrm{F}}=\mathrm{CF}\left(\mathrm{CF}_{3}\right) \mathrm{OC}_{4} \mathrm{~F}_{9} \quad(\mathrm{DV}-\mathrm{Si}) \quad\left[\mathrm{R}_{\mathrm{F}}-(\mathrm{DV}-\mathrm{Si}-\mathrm{Vinyl})_{x}-\mathrm{R}_{\mathrm{F}}\right]
\end{aligned}
$$

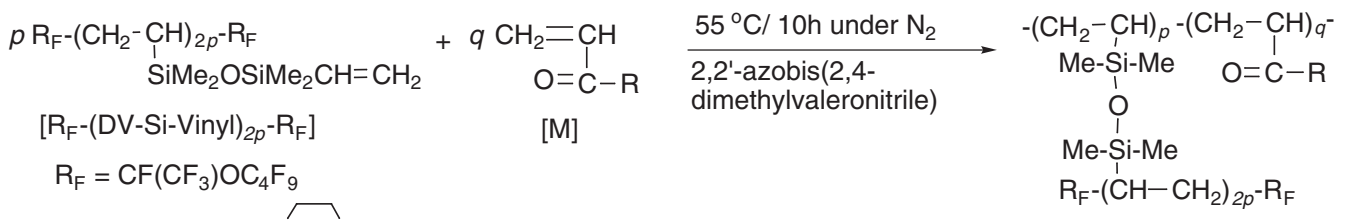

$$
\begin{aligned}
& \mathrm{R}=\mathrm{OH}, \mathrm{NMe}_{2}, \stackrel{\mathrm{O}}{\mathrm{O}}
\end{aligned}
$$

Scheme 11.

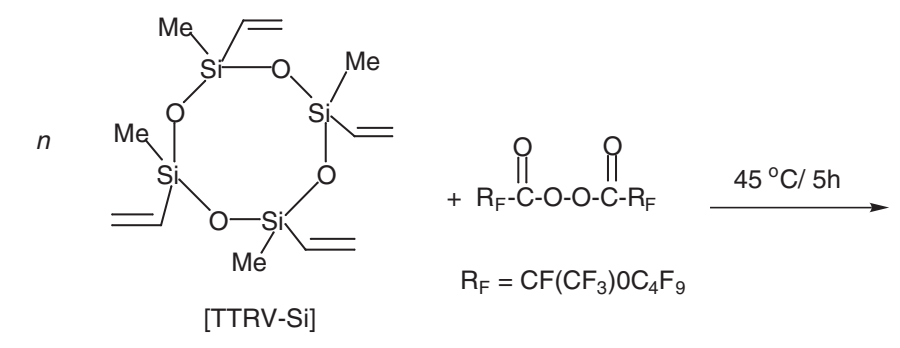

$$
\begin{aligned}
& \mathrm{R}_{\mathrm{F}}-\left(\mathrm{CH}_{2}-\mathrm{CH}\right)_{n}-\mathrm{R}_{\mathrm{F}} \\
& \left.\mathrm{R}_{\mathrm{F}}-(\mathrm{TTRV}-\mathrm{Si})_{n}-\mathrm{R}_{\mathrm{F}}\right] \\
& \mathrm{CF}\left(\mathrm{CF}_{3}\right) \mathrm{OC}_{4} \mathrm{~F}_{9}
\end{aligned}
$$

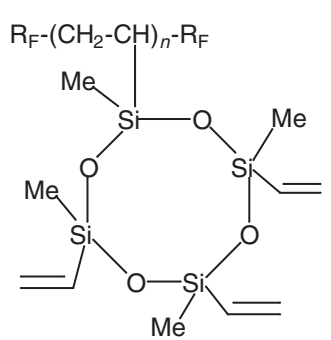

$\left[\mathrm{R}_{\mathrm{F}}-(\mathrm{TTRV}-\mathrm{Si})_{n}-\mathrm{R}_{\mathrm{F}}\right]$

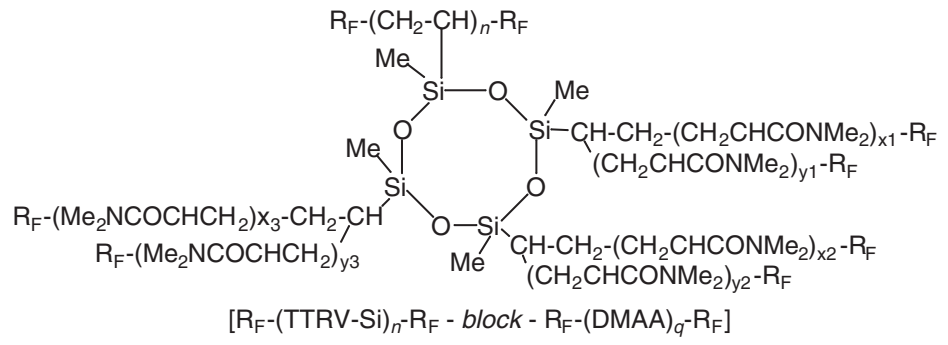

Scheme 12.

Fluoroalkanoyl peroxide reacted 1,3,5,7-tetravinyl1,3,5,7-tetramethylcyclotetrasiloxane to afford fluoroalkyl end-capped oligomers containing certain unreacted vinyl segments under very mild conditions (see Scheme 12). ${ }^{37}$ Fluoroalkyl end-capped cyclosiloxane oligomers containing some vinyl groups thus obtained reacted with $\mathrm{N}, \mathrm{N}$-dimethylacrylamide and fluoroalkanoyl peroxide to afford new fluorinated dendritic-type block copolymers in good isolated yields. ${ }^{37}$ The fluorinated dendritic-type block copolymers had excellent solubility not only in water but also in traditional organic solvents including aliphatic fluorinated solvents. The fluorinated dendritic-type block copolymers formed nanometer size-controlled self-assembled molecular aggregates produced by the aggrega- tion of terminal fluoroalkyl segments in the block copolymers in aqueous solution (see Figure 10). The fluorinated block copolymers showed extremely higher dispersion toward not only single-walled carbon nanotubes but also fullerenes compared to two fluoroalkyl end-capped $\mathrm{N}, \mathrm{N}$-dimethylacrylamide oligomers. ${ }^{37}$

\section{PREPARATION AND APPLICATION OF FLUOROALKYL END-CAPPED OLIGOMERS/ SILICA GEL NANOCOMPOSITES}

Fluoroalkyl end-capped oligomers form nanometer size-controlled self-assembled molecular aggregates through the aggregation of end-capped fluoroalkyl 

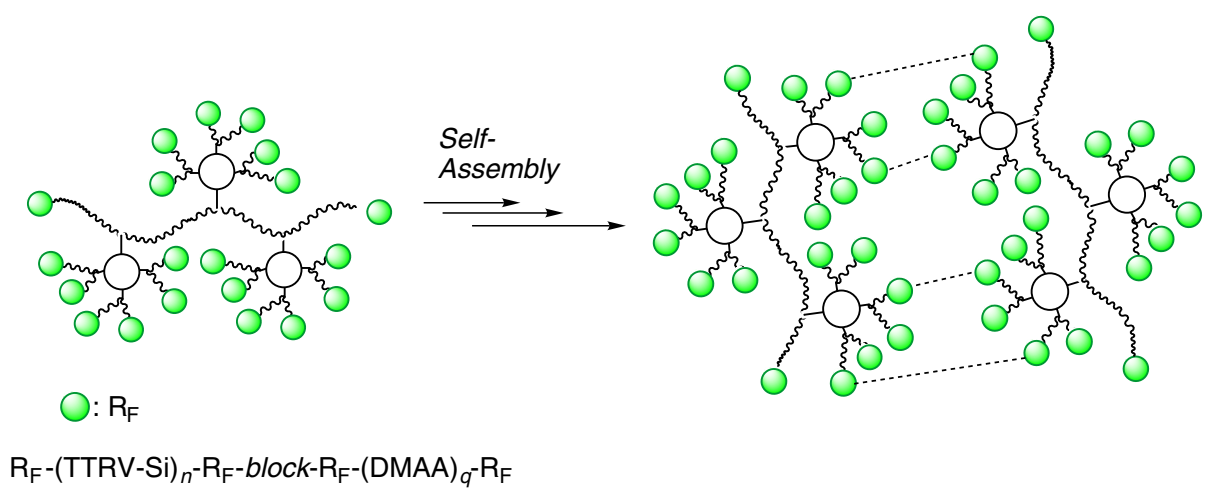

$\mathrm{R}_{\mathrm{F}}-(\mathrm{TTRV}-\mathrm{Si})_{n}-\mathrm{R}_{\mathrm{F}}-$ block- $\mathrm{R}_{\mathrm{F}}-(\mathrm{DMAA})_{q}-\mathrm{R}_{\mathrm{F}}$

Figure 10. Formation of self-assembled molecular aggregates of $R_{F}-(T T R V-S i)_{n}-R_{F}-$ block- $R_{F}-(D M A A)_{q}-R_{F}$.

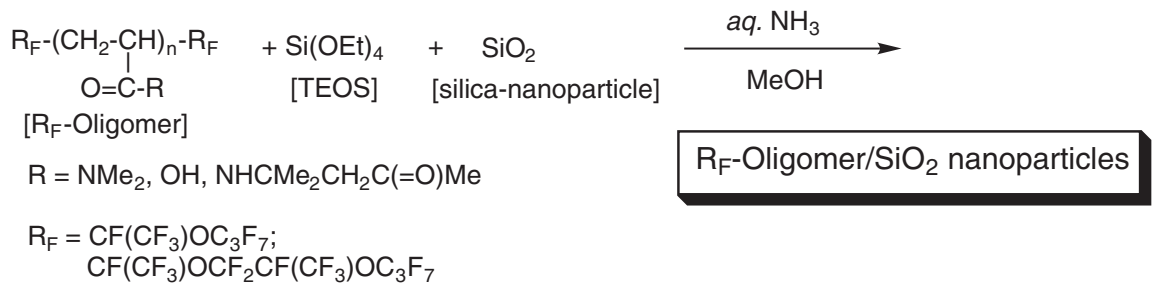

Scheme 13.

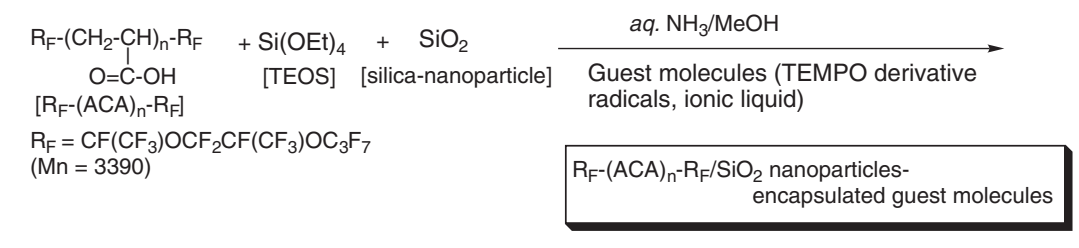

TEMPO derivative radicals

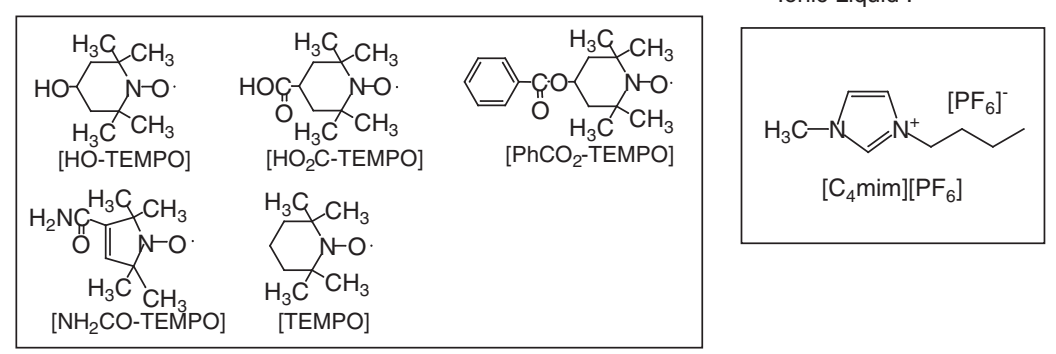

Scheme 14.

segments to interact with a variety of guest molecules. Fluorinated molecular aggregate shape would easily change under a variety of conditions. Thus, new fluoroalkyl end-capped oligomer-coated nanoparticles should be prepared with structures fixed from a developmental viewpoint of new fluorinated functional material. The authors have prepared a variety of fluoroalkyl end-capped oligomers by reaction of the corresponding oligomers with tetraethoxysilane (TEOS) and silica nanoparticles under alkaline conditions (see Scheme 13). ${ }^{38}$

The fluorinated oligomer silica particle powders obtained afforded nanometer size-controlled colloidal particles with good redispersibility and stability in media. Fluoroalkyl end-capped oligomers/silica nanoparticles-encapsulated guest molecules such as stable organic radicals and ionic liquids were prepared under similar conditions (see Scheme 14) ${ }^{37}$ The fluorinated nanoparticles-encapsulated guest molecules were applied to a new type of surface modification agent, and these particles dispersed well above poly(methyl methacrylate) films. ${ }^{38}$

Fluoroalkyl end-capped acrylic acid oligomer/ silica nanocomposite $\left[\mathrm{R}_{\mathrm{F}}-(\mathrm{ACA})_{\mathrm{n}}-\mathrm{R}_{\mathrm{F}} /\right.$ silica gel nanocomposites; average particle size: $31 \mathrm{~nm}$ ] and fluoroalkyl end-capped N-(1,1-dimethyl-3-oxobutyl)acrylamide oligomer $\left[\mathrm{R}_{\mathrm{F}}-(\mathrm{DOBAA})_{\mathrm{n}}-\mathrm{R}_{\mathrm{F}} /\right.$ silica gel nanocomposite of average particle size: $36 \mathrm{~nm}$ ] were 
prepared under similar conditions as in Scheme 13 (see Scheme 15).

In Figure 12, the weight of parent $R_{F}-(A C A)_{n}-R_{F}$ oligomer markedly drops around $250^{\circ} \mathrm{C}$ and decomposes gradually, reaching $0 \%$ around $540{ }^{\circ} \mathrm{C}$. The same was observed in $\mathrm{R}_{\mathrm{F}}-(\mathrm{ACA})_{\mathrm{n}}-\mathrm{R}_{\mathrm{F}} / \mathrm{SiO}_{2}$ nanocomposite and a constant value for weight loss was observed above $540{ }^{\circ} \mathrm{C}$, indicating that this nanocomposite could possess silica gel nanoparticles. Parent $\mathrm{R}_{\mathrm{F}^{-}}$ $(\mathrm{ACA})_{\mathrm{n}}-\mathrm{R}_{\mathrm{F}}$ oligomer in this nanocomposite was estimated to be $26 \%$ from TGA (thermogravimetric analyses) data, this value being nearly the same as that (22\%) by the elementary analysis of fluorine. In Figure 13, there is no weight loss of $\mathrm{R}_{\mathrm{F}}-(\mathrm{DOBAA})_{\mathrm{n}}$ $\mathrm{R}_{\mathrm{F}}$ oligomers $/ \mathrm{SiO}_{2}$ nanocomposite from room temperature to $800^{\circ} \mathrm{C}$ equal to the original silica gel, although the parent $\mathrm{R}_{\mathrm{F}}-(\mathrm{DOBAA})_{\mathrm{n}}-\mathrm{R}_{\mathrm{F}}$ oligomer lost $100 \%$ its weight at $600{ }^{\circ} \mathrm{C}$. $\mathrm{R}_{\mathrm{F}}-(\mathrm{DOBAA})_{\mathrm{n}}-\mathrm{R}_{\mathrm{F}}$ oligo$\mathrm{mer} / \mathrm{SiO}_{2}$ nanocomposite lost only $6 \%$ its weight at $800^{\circ} \mathrm{C}$, this being the same value as for the original silica gel. This indicates that pyrolytic fragments of $\mathrm{R}_{\mathrm{F}}-(\mathrm{DOBAA})_{\mathrm{n}}-\mathrm{R}_{\mathrm{F}}$ oligomer should be encapsulated effectively into silica gel matrices. The average particle size $\left[37.1 \pm 4.8 \mathrm{~nm}\right.$ (determined by DLS) of $\mathrm{R}_{\mathrm{F}}-$ (DOBAA) $)_{n}-\mathrm{R}_{\mathrm{F}}$ oligomer $/ \mathrm{SiO}_{2}$ nanocomposite after calcination was almost the same as that $(36.2 \pm 3.3$ $\mathrm{nm}$ ) before calcination, and good dispersibility and stability in a variety of solvents were showed. ${ }^{39}$

TGA/Mass spectra of fluorinated nanocomposite

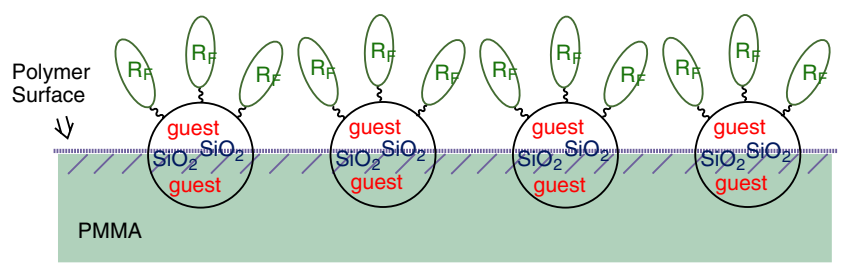

Figure 11. Schematic Illustration for the Arrangement of $\mathrm{R}_{\mathrm{F}^{-}}$ Oligomers $/ \mathrm{SiO}_{2}$ Nanoparticles-encapsulated Guest Molecules above the Polymer Surface. showed this nanocomposite to decompose around $280^{\circ} \mathrm{C}$ to afford $\mathrm{CO}_{2}$ and $\mathrm{H}_{2} \mathrm{O}$ as the major evolved gaseous products including some minor fluoro- and

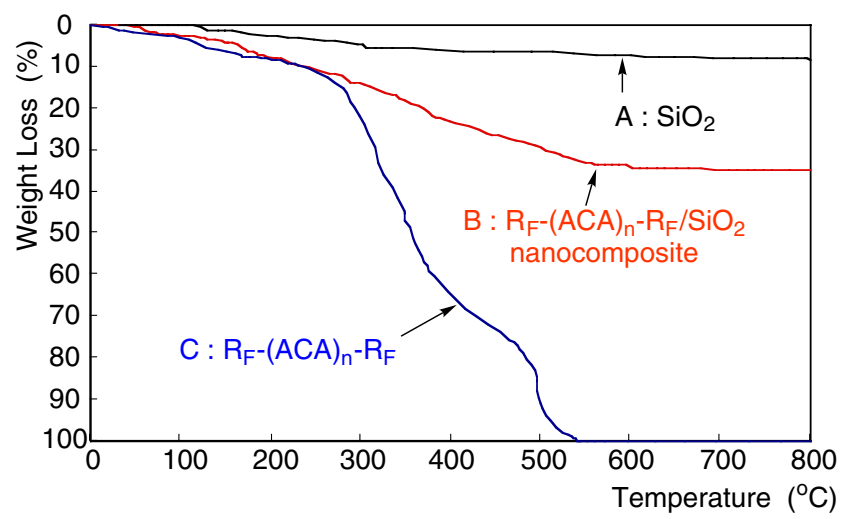

Figure 12. Thermogravimetric analysis of $R_{F}-(A C A)_{n}-R_{F} /$ $\mathrm{SiO}_{2}$ nanocoposite $\left[\mathrm{R}_{\mathrm{F}}=\mathrm{CF}\left(\mathrm{CF}_{3}\right) \mathrm{OC}_{3} \mathrm{~F}_{7}\right]$.

A: $\mathrm{SiO}_{2}$

B: $\mathrm{R}_{\mathrm{F}}-(\mathrm{ACA})_{\mathrm{n}}-\mathrm{R}_{\mathrm{F}} / \mathrm{SiO}_{2}$ nanocomposite

C: $R_{F}-(A C A)_{n}-R_{F}$

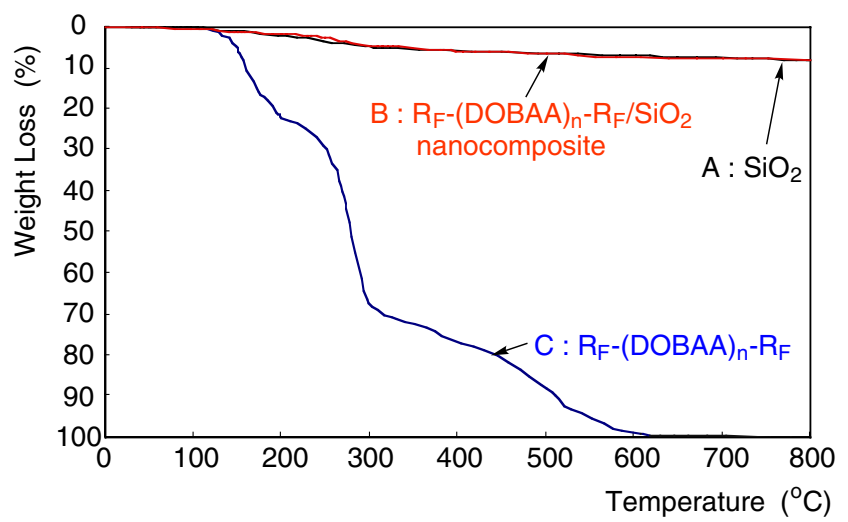

Figure 13. Thermogravimetric analysis of $\mathrm{R}_{\mathrm{F}}-(\mathrm{DOBAA})_{n^{-}}$ $\mathrm{R}_{\mathrm{F}} / \mathrm{SiO}_{2}$ nanocomposite $\left[\mathrm{R}_{\mathrm{F}}=\mathrm{CF}\left(\mathrm{CF}_{3}\right) \mathrm{OC}_{3} \mathrm{~F}_{7}\right]$.

A: $\mathrm{SiO}_{2}$

B: $\mathrm{R}_{\mathrm{F}}-(\mathrm{DOBAA})_{\mathrm{n}}-\mathrm{R}_{\mathrm{F}} / \mathrm{SiO}_{2}$ nanocomposite

$C: R_{\mathrm{F}}-(\mathrm{DOBAA})_{\mathrm{n}}-\mathrm{R}_{\mathrm{F}}$

$$
\begin{aligned}
& \begin{array}{c}
\mathrm{R}_{\mathrm{F}}-\left(\mathrm{CH}_{2}-\mathrm{CH}\right)_{n}-\mathrm{R}_{\mathrm{F}} \\
\mathrm{O}=\mathrm{C}-\mathrm{R}^{1}
\end{array}+\begin{array}{r}
\mathrm{Si}(\mathrm{OEt})_{4} \\
{[\text { TEOS] }}
\end{array} \\
& \mathrm{R}_{\mathrm{F}}=\mathrm{CF}\left(\mathrm{CF}_{3}\right) \mathrm{OC}_{3} \mathrm{~F}_{7} \\
& \text { [R } \mathrm{R}_{\mathrm{F}} \text {-Oligomer] } \\
& {\left[\begin{array}{l}
\mathrm{R}^{1}=\mathrm{NHC}\left(\mathrm{CH}_{3}\right)_{2} \mathrm{CH}_{2} \mathrm{C}(=\mathrm{O}) \mathrm{CH}_{3} ;(\mathrm{DOBAA}) \\
\mathrm{R}^{1}=\mathrm{OH} ;(\mathrm{ACA})
\end{array}\right]}
\end{aligned}
$$
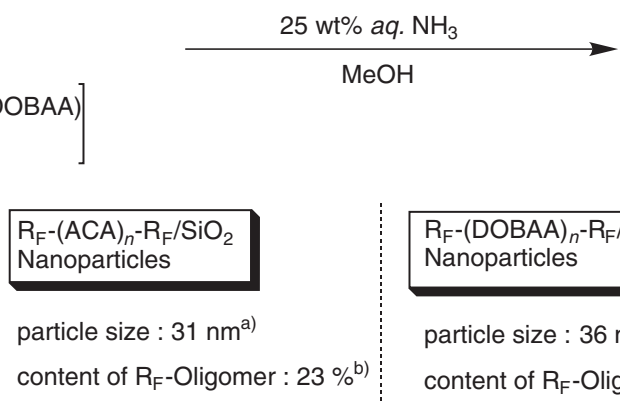

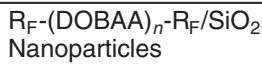

particle size : $36 \mathrm{~nm}^{\text {a) }}$ content of $\mathrm{R}_{\mathrm{F}}$-Oligomer : $22 \%{ }^{\mathrm{b})}$

a) Determined by DLS

b) Determined by elementary analyses of fluorine

Scheme 15. 


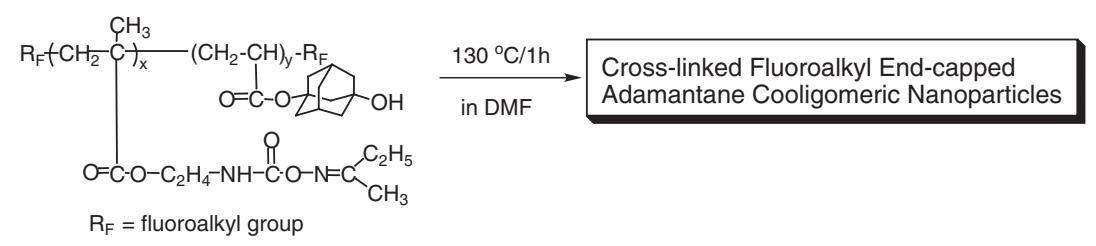

Scheme 16.

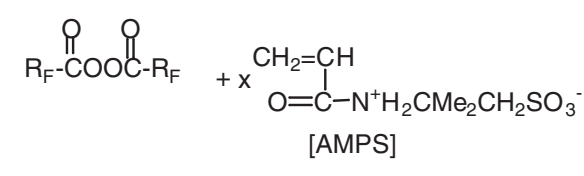

$\mathrm{R}_{\mathrm{F}}=\mathrm{CF}\left(\mathrm{CF}_{3}\right) \mathrm{OCF}_{2} \mathrm{CF}\left(\mathrm{CF}_{3}\right) \mathrm{OC}_{3} \mathrm{~F}_{7}$

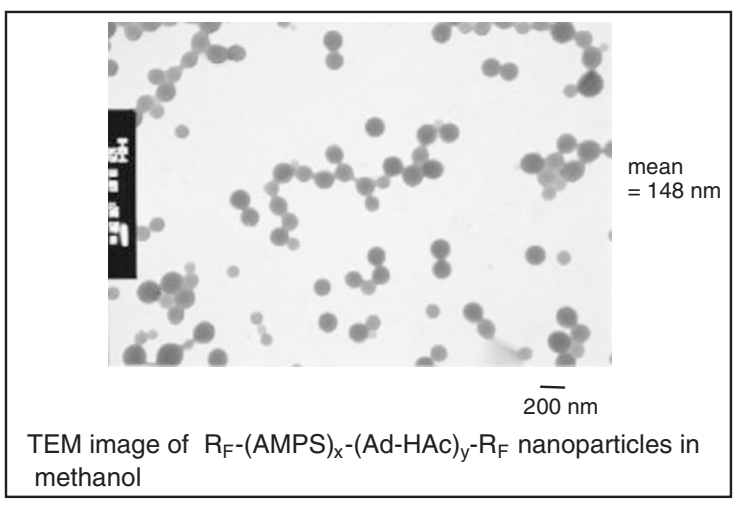

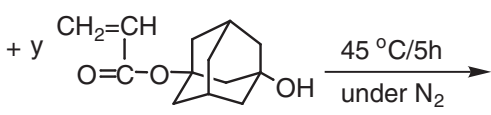

[Ad-HAc]

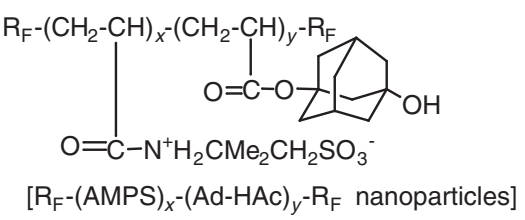

$\left[\mathrm{R}_{\mathrm{F}}-(\mathrm{AMPS})_{x}-(\mathrm{Ad}-\mathrm{HAc})_{y}-\mathrm{R}_{\mathrm{F}}\right.$ nanoparticles]

Scheme 17.

hydro-carbons. The evolved gaseous products may thus possibly be encapsulated quantitatively into nanometer-size controlled silica matrices to give a fluorinated silica gel nanocomposite with no weight loss even at $800{ }^{\circ} \mathrm{C}$ as noted for the original silica gel. ${ }^{39}$

\section{PREPARATION AND APPLICATION OF CROSS-LINKED FLUOROALKYL END- CAPPED OLIGOMERIC NANOPARTICLES}

From a developmental viewpoint of new nanoscale materials, novel polymer nanoparticles possessing unique characteristics such as surface active properties imparted by fluorine should be produced. However, studies on the development of such fluorinated polymeric nanoparticles are very limited, although these studies have been the subject of considerable research of a fundamental and applied nature. The authors prepared new cross-linked fluoroalkyl endcapped cooligomeric nanoparticles containing adamantane segments by deprotecting reaction of oxime-blocked isocyanato segments in cooligomers. The thermal stability of these cross-linked fluorinated cooligomeric nanoparticles containing adamantane segments was found to greatly increase compared to the parent fluorinated cooligomer. The thermal stability of these cross-linked fluorinated nanoparticles was

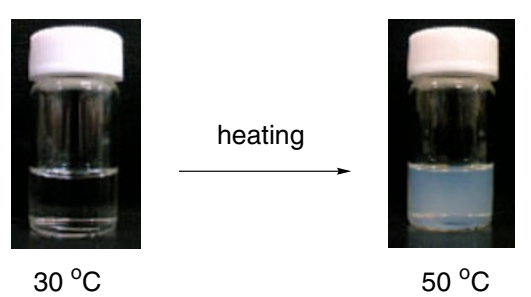

Figure 14. Photographys of t-butyl alcohol solutions of $\mathrm{R}_{\mathrm{F}^{-}}$ $(A M P S)_{x}-(A d-H A c)_{y}-R_{F}\left(6 \mathrm{~g} / \mathrm{dm}^{3}\right)$ possessing LCST characteristic.

almost the same for fluoroalkyl end-capped acrylic acid oligomer $/ \mathrm{SiO}_{2}$ nanocomposites (content of $\mathrm{SiO}_{2}$ in composites: 70\%). The cross-linked fluorinated nanoparticles were applied to surface modification of traditional organic polymers such as poly(methyl methacrylate) to exhibit good oleophobicity due to fluorine on the surface. ${ }^{40}$

A new type of thermosensitve fluoroalkyl endcapped 2-acrylamide-2-methylpropane sulfonic acid (AMPS) cooligomeric nanoparticles containing adamantyl segments was prepared and found to exhibit LCST (Lower Critical Solution Temperature) characteristic in organic media. ${ }^{41}$ The present fluoroalkyl end-capped AMPS cooligomeric nanoparticles exhibit LCST around $50^{\circ} \mathrm{C}$ in organic media such as $t$-butyl 
alcohol. Possibly, the present LCST behavior may be mainly related to oleophilic-oleophobic balance in cooligomeric nanoparticles corresponding to oleophilicity from adamantyl segments and the oleophobicity from fluoroalkyl groups. ${ }^{40}$ Our present LCST observation in organic media may quite possibly be due to the oleophobicity caused by fluoroalkyl groups.

\section{CONCLUSION}

Fluoroalkanoyl peroxide exhibits quite different decomposition behavior from the corresponding non-fluorinated alkanoyl peroxides, owing to the strong electron-withdrawing properties by fluoroalkyl groups. The presence of two fluoroalkyl groups in alkanoyl peroxides can greatly weaken $\mathrm{O}-\mathrm{O}$ bonds in addition to lowering the energy level of the antibonding $\mathrm{O}-\mathrm{O}$ bonds compared to the corresponding nonfluorinated peroxides. These unique characterisitics of fluoroalkanoyl peroxides were applied for the direct introduction of fluoroalkyl groups into aromatic polymers such as polystyrenes, polydiphenylsilane, polydiphenylsiloxane, polyimide and polyamic acid, and end-sites of vinylsilane and (meth)acrylate oligomers via a single electron transfer and a radical process, respectively. Fluoroalkyl end-capped oligomers were applied to surface modification of glass and a variety of organic polymers to exhibit a good surface active property imparted by end-capped fluoroalkyl groups on the surface. The fluoroalkyl end-capped oligomers formed nanometer size-controlled selfassembled molecular aggregates by aggregation of end-capped fluoralkyl groups in oligomers in aqueous and organic media. The fluorinated oligomeric aggregates provide suitable host moieties to interact with a variety of guest molecules such as low molecular biocides, hydrophilic amino and N,N-dimethylamino compounds, fullerenes, and carbon nanotubes. Fluoroalkyl end-capped oligomers/silica gel nanocomposites and cross-linked fluoroalkyl end-capped oligomeric nanoparticles are prepared under mild conditions using the corresponding oligomers, and the nanocomposites and nanoparticles were applied to surface modification of traditional organic polymers. The fluorinated oligomeric compounds should thus be widely applicable to numerous fields as new fluorinated functional polymeric material.

Acknowledgment. The author gratefully appreciates the financial support from a grant-in-aid for Scientific Research from the Ministry of Education, Science, Sports and Culture, Japan. The author also thanks to NOF Corporation, Fujikura Rubber Ltd. and Asahi Glass Co., Ltd. for helpful discussions and financial support.

\section{REFERENCES}

1. B. Ameduri and B. Boutevin, "Well-Architectured Fluoropolymers: Synthesis, Properties and Applications," Elsevier, Amsterdam, 2004, pp231-348.

2. a) Y. Tanizaki, J. Jpn. Oil Chem. Soc., 34, 973 (1985).

b) P. Anton, O. Koberle, and A. Laschewsky, Makromol. Chem., 194, 1 (1993).

c) D. Cochin, P. Hendlinger, and A. Laschewsky, Colloid Polym. Sci., 273 (1995) 1138.

d) I. J. Park, S.-B. Lee, C. K. Choi, and K.-J. Kim, J. Colloid Interface Sci., 181, 284 (1996).

e) I. J. Park, S.-B. Lee, and C. K. Choi, J. Appl. Polym. Sci., 54, 1449 (1994).

3. a) J.-F. Berret, D. Calvet, A. Collet, and M. Viguier, Curr. Opin. Colloid Interface Sci., 8, 296 (2003).

b) T. Imae, Curr. Opin. Colloid Interface Sci., 8, 307 (2003). c) T. Imae, H. Tabuchi, K. Funayama, A. Sato, T. Nakamura, and N. Amaya, Colloid Surf. A: Physicochem. Eng. Aspects, 167, 73 (2000).

4. a) P. Lebreton, B. Ameduri, B. Boutevin, and J. M. Corpart, Macromol. Chem. Phys., 203, 522 (2002).

b) M. Destarac, D. Charmot, S. Zard, and X. Franck, WO 00/75207 A1 (2000).

c) M. J. Monteiro, M. M. Adamy, B. J. Leeuwen, A. M. Van Herk, and M. Destarac, Macromolecules, 38, 1538 (2005).

d) A. E. Feiring, E. R. Wonchoba, F. Davdson, V. Percec, and B. Barboiu, J. Polym. Sci. Part A: Polym. Chem., 38, 3313 (2000).

e) W. Ming, R. D. Van de Grampel, A. Gildenpfemmig, A. Snijder, H. H. Brongersma, R. Van de Linde, and G. De With, Polym. Mater. Sci. Eng., 88, 517 (2003).

f) M. Destarac, K. Matyjaszewski, E. Silverman, B. Ameduri, and B. Boutevin, Macromolecules, 33, 4613 (2000).

g) Z. Shi and S. Holdcroft, Macromolecules, 38, 4193 (2005).

h) K. Jankova and S. Hvilsted, J. Fluorine Chem., 126, 241 (2005).

5. a) H. Sawada, Chem. Rev., 96, 1779 (1996).

b) H. Sawada, J. Fluorine Chem., 105, 219 (2000).

c) C. Corvaja, A. Famulari, L. Franco, M. Galimberti, P. Metrangold, W. Navarrini, G. Resnati, and M. Sansotera, Chem. Today, 24, No. 3, p16, Focus on Fluoirne Chemistry.

6. a) K. Oharu, T. Seki, K. Ohira, H. Nakagaea, and H. Sawada, Tokkyo Koho, JP 2003, 155272.

b) K. Oharu, M. Sato, K. Ohira, H. Nakagawa, and H. Sawada, Tokkyo Koho, JP 2003, 160578.

c) K. Oharu, K. Watanabe, K. Ohira, H. Nakagawa, and H. Sawada, Tokkyo Koho, JP 2003, 160579.

d) H. Sawada, M. Kurachi, K. Takishita, T. Tanedani, T. Terasawa, Y. Hayakawa, and T. Kawase, Eur. Polym. J., 37, 1409 (2001).

e) H. Sawada, M. Kurachi, T. Maekawa, T. Kawase, Y. Hayakawa, K. Takishita, and T. Tanedani, J. Appl. Polym. Sci., 72, 1101 (1999).

7. H. Sawada, M. Nakayama, O. Kikuchi, and Y. Yokoyama, J. Fluorine Chem., 50, 393 (1990). 
8. H. Sawada, "Polymeric Materials Encyclopedia-Synthesis, Properties and Applications," Vol. 4, J. C. Salamone, Ed., CRC Press, Inc., Florida, 1996, p2507.

9. H. Sawada, Y.-F. Gong, Y. Minoshima, T. Matsumoto, M. Nakayama, M. Kosugi, and T. Migita, J. Chem. Soc., Chem. Commun., 537 (1992).

10. H. Sawada, Y. Minoshima, and H. Nakajima, J. Fluorine Chem., 65, 169 (1992).

11. M. Hasegawa, T. Hirano, M. Seno, and T. Sato, Polym. Prepr., Jpn., 54(1), 123 (2005).

12. H. Sawada and M. Nakayama, J. Chem. Soc., Chem. Commun., 677 (1991).

13. H. Sawada, J. Fluorine Chem., 121, 111 (2003).

14. H. Sawada, "Polymeric Materials Encyclopedia-Synthesis, Properties and Applications," Vol. 4, J. C. Salamone, Ed., CRC Press, Inc., Florida, 1996, p2539.

15. O. W. Steward and O. R. Pierce, J. Org. Chem., 26, 2943 (1961).

16. H. Takahashi and H. Sawada, Japan Patent No. 3645517 (Feb. 10, 2005).

17. H. Sawada, N. Itoh, T. Kawase, M. Mitani, H. Nakajima, M. Nishida, and Y. Moriya, Langmuir, 10, 994 (1994).

18. a) J. Nakagawa, K. Kamogawa, H. Sakai, T. Kawase, H. Sawada, J. Manosroi, A. Manosroi, and M. Abe, Langmuir, 14, 2055 (1998).

b) J. Nakagawa, K. Kamogawa, N. Momozawa, H. Sakai, T. Kawase, H. Sawada, Y. Sano, and M. Abe, Langmuir, 14, 2061 (1998).

19. H. Sawada. K. Tanba, N. Itoh, C. Hosoi, M. Oue, M. Baba, T. Kawase, M. Mitani, and H. Nakajima, J. Fluorine Chem., 77, 51 (1996).

20. a) H. Sawada, S. Katayama, Y. Nakamura, T. Kawase, Y. Hayakawa, and M. Baba, Polymer, 39, 743 (1998).

b) H. Sawada, S. Katayama, Y. Ariyoshi, T. Kawase, Y. Hayakawa, T. Tomita, and M. Baba, J. Mater. Chem., 8, 1517 (1998).

21. M. Fujiwara, N. Ashida, M. Okamoto, T. Mizuta, T. Ide, Y. Hanasaki, K. Katsuura, H. Sawada, S. Shigeta, K. Konno, T. Yokota, and M. Baba, Antiviral Res., 38, 141 (1998).

22. H. Sawada, Y. Ariyoshi, K. Lee, J. Kyokane, and T. Kawase, Eur. Polym. J., 36, 2523 (2000).

23. H. Sawada, K. Ikeno, and T. Kawase, Macromolecules, 35, 4306 (2002).

24. H. Sawada, Y. Yoshino, M. Kurachi, T. Kawase, K. Takishita, and T. Tanedani, Polymer, 41, 397 (2000).
25. H. Sawada, K. Yanagida, R. Takahashi, Y. Nishikawa, T. Kawase, K. Oharu, H. Nakagawa, K. Ohira, and K. Wada, Polym. J., 34, 855 (2002).

26. a) X. Gong, T. Milic, C. Xu, J. D. Batteas, and C. M. Drain, J. Am. Chem. Soc., 124, 14290 (2002).

b) S. Takahashi, H. Miura, H. Kasai, S. Okada, H. Oikawa, and H. Nakanishi, J. Am. Chem. Soc., 124, 10944 (2002). c) H.-B. Fu and J.-N. Yao, J. Am. Chem. Soc., 123, 1434 (2001).

27. B.-K. An, S.-Ki. Kwon, S.-D. Jung, and S. Y. Park, J. Am. Chem. Soc., 124, 14410 (2002).

28. K. Sasazawa, Y. Yamada, A. Fujisawa, T. Saitoh, K. Ueno, K. Oharu, and H. Sawada, Colloid Polym. Sci., 283, 812 (2005).

29. a) T. Tokuyama, S. Yamago, E. Nakamura, T. Shiraki, and Y. Sugiura, J. Am. Chem. Soc., 115, 7918 (1993).

b) S. H. Friedman, D. L. Decamp, R. P. Sijbesma, G. Srdanov, F. Wudl, and G. L. Kenyon, J. Am. Chem. Soc., 115, 6506 (1993).

30. Y. N. Yamakoshi, T. Yagami, K. Fukuhara, S. Sueyoshi, and N. Miyata, J. Chem. Soc., Chem. Commun., 116, 517 (1994).

31. H. Sawada, J. Iidzuka, T. Maekawa, R. Takahashi, T. Kawase, K. Oharu, H. Nakagawa, and K. Ohira, J. Colloid Interface Sci., 263, 1 (2003).

32. H. Sawada, J. Iidzuka, T. Kawase, K. Oharu, and H. Nakagawa, Eur. Polym. J., 39, 1991 (2003).

33. Special Issue Carbon Nanotubes, Acc. Chem. Res., 35, No. 12 (2002).

34. M. J. O'Connell, P. Boul, L. M. Ericson, C. Huffman, Y. Wang, E. Haroz, C. Kuper, J. Tour, K. D. Ausman, and R. E. Smalley, Chem. Phys. Lett., 342, 265 (2001).

35. H. Sawada, K. Shindo, J. Iidzuka, K. Ueno, and K. Hamazaki, Eur. Polym. J., 41, 2232 (2005).

36. H. Sawada, M. Suzuki, and M. Mugisawa, Polym. Adv. Technol., 17, 66 (2006).

37. H. Yoshioka, M. Suzuki, M. Mugisawa, N. Naitoh, and H. Sawada, J. Colloid Interface Sci., 308, 4 (2007).

38. H. Sawada, T. Narumi, A. Kajiwara, K. Ueno, and K. Hamazaki, Colloid Polym. Sci., 284, 551 (2006).

39. H. Sawada, T. Narumi, S. Kodama, M. Kamijo, R. Ebara, M. Sugiya, and Y. Iwasaki, Colloid Polym. Sci., in press.

40. M. Mugisawa, K. Ueno, K. Hamazaki, and H. Sawada, Macromol. Rapid Commun., in press.

41. M. Mugisawa, K. Ohishi, and H. Sawada, Langmuir, in press.

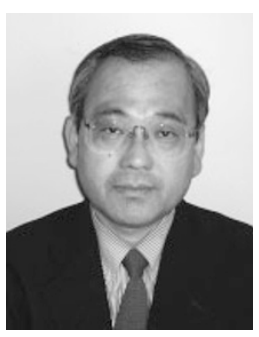

Hideo Sawada was born in Gunma, Japan, on February 9, 1956. He received his B.S. degree in 1978 from Gunma University and M.S. degree in 1980 from Tokyo Metropolitan University. He was associated with NOF Corporation from 1980 and received his Ph.D. degree in 1986 from Tokyo Metropolitan University. In 1993, he accepted a position as Associate Professor at Nara National College of Technology, and he became a Professor of Chemistry at the Nara National College of Technology in 2000. In 2002, he moved to Hirosaki University as a Professor of Polymer Chemistry. His current research interests concern the synthesis and applications of fluorinated oligomers using fluoroalkanoyl peroxides. He received the Progress Award of the Japan Oil Chemists' Society in 1992, the Award of the Japan Society of Colour Materials in 1994, the Award of the Japan Research Institute of Material Technology in 1996, and the SPSJ Mitsubishi Chemical Award in 2006. He is a member of the Editorial Boards of the Journal of Fluorine Chemistry. 